\title{
Internal Assessment as Predictor of External Evaluation in A Senior High School in Ghana: An Exploratory Case Study
}

\author{
Issifu A. Amadu ${ }^{1 *} \quad$ Ezekiel Seudib ${ }^{2}$ \\ 1.SAEMS, University for Development Studies, PO box TL1350, Tamale, Ghana \\ 2.IDL, Kwame Nkrumah University Science and Technology, Private Mail Bag, Kumasi, Ghana
}

\begin{abstract}
This study explored the relationship between performance of senior secondary school students in internal tests (school/teacher generated) and external assessments conducted by West Africa Secondary School Certificate Examination (WASSCE) in Ghana. A deductive comparative design approach was used for the study. A longitudinal data consisting of 111 student scores together with their corresponding scores in internal and external assessments spanning their second cycle education in a purposively selected public senior secondary school between 2013 and 2016 in the Bono East region for the study. Specifically, the study aimed at determining if there existed any significant difference between external and internal performance of students in core mathematics. Based on the data, a predictive model for overall student assessment with particular reference to the selected case was formulated. Data was analysed using statistical tools such descriptive statistics, correlation coefficients, paired sample t-test and regression analysis. The results were presented using tables and graphs. The study revealed a positive relationship between internal assessments marks and external assessment scores in core mathematics with the internal assessment scores being an important forecaster of student external assessment scores. Based on the findings, the study recommends that teachers engage students seriously in the teaching of mathematics while they are in the school, since that contributes considerably in predicting students' performance in external assessment.
\end{abstract} Keywords: internal assessment, external assessment, high school, models

DOI: $10.7176 / \mathrm{JEP} / 12-3-07$

Publication date: January $31^{\text {st }} 2021$

\section{Introduction}

In every system of education, students are often tested /examined in order to ascertain their level of understanding in lessons taught in class. The Cambridge dictionary defines assessment as the mode of judging or settling on the amount, significance of a thing or the conclusion or decision taken on a fair ground where elements of bias are kept under absolute control

(http://dictionary.cambridge.org/dictionary/english/assessment). Within the scope of this study, assessment is understood to imply the medium through which an assessor is able to determine the worth (inferiority and superiority) or recall capacity of students on a subject content they have been taught in the classroom by their teachers or other facilitators or students self-guided studies.

Furthermore, educational assessment is the medium through which students are made to document, usually in quantifiable terms, a thing, event, situation or field to enable the teacher to determine the knowledge base of the student. It is an instrument for gathering information through tests of various forms about the performance or capabilities of individuals, which is often used interchangeably with tests. According to Fernley (2015), assessment enable teachers or trainers gauge a learner, learners, learning group, class, organisation or the whole system of education (normally referred to as granularity). Assessment as a concept within the framework of education gained popularity after the Second World War (Nelson, 2014).

Aijaz (2011) posits that internal assessment is often called "home examination", "Classroom test" or

"Teacher made test". According to the author, internal assessment could also be in a form in which all the arrangements are handled by the teachers of the same institution. The author further states that the main aim of internal assessments is to evaluate/assess the progress of school children in different classes at different levels. In assessments of this kind, the teachers themselves frame the questions, and examine the scripts/answers and decide on criteria for success (this usually graded: pass, good, credit, high credit, excellent etcetera) or failure (Aijaz, 2011).

Internal assessments have several objectives among which include: to assess/evaluate the cognitive capability of students, and also to estimate students' educational progress, speed of achievement and learning ability (Aijaz, 2011). Internal assessments bring numerous benefits to learners and teachers alike; making it indispensable at school level student performance evaluation. Other researchers have opined that the benefits of student assessments are varied; the most important being the competitive environment it creates among learners at all levels. It equally enables students and teachers know student achievement levels to inform the necessary remedial action; thus, students who are performing consistently well and those lagging behind and by how much. This enables teachers to reorient their teaching methods and try to overcome weaknesses in teaching and learning (Mufanechiya, 2013). Additionally, parents need to be informed about the progress of their children during each 
new school year; through this parents and teachers can tackle challenges that confront teaching and learning in school and finally, through internal assessments teachers identify hidden abilities, capabilities, desires and interests of the students so as to guide them accordingly (Aijaz, 2011).

Generally, challenges that confront internal assessments include the following: indiscreet comparison of students, as grades may vary from one school to the rest in the absence of any standard uniformity criteria, and therefore student scores may not have any serious comparative ability. Also, it has been argued that teachers usually have freedom of evaluating their own students and may tend to be lax in scoring student assignments (Aijaz, 2011).

Going further, Nsgmedico (2014) considered external assessment as one which is set by a governing body and is marked by non-biased personnel and that external assessments are designed, selected, and controlled by another person or group of commercial examiners, district administrators, or state policymakers. Thus, organisation and arrangement of external assessment is often carried out by an independent person, group or agency other than the school whose students are examined, using standardised tests, observations and other techniques. In a nutshell, external assessments are perceived to be more objective, standardised and independent of all forms of control. Unlike internal assessments, external assessments are conducted with the sole objective of awarding terminal certificates in tandem with national priorities (Nsgmedico, 2014). However, external assessments are bedevilled with challenges; the only feedback is usually a grade at the end of the course; no opportunities for interaction with assessors for further feedback (Nsgmedico, 2014).

Internal examinations have become an integral part of Ghana's educational system for decades and serves as a yardstick for teachers, students and parents to monitor the preparedness of students for final external examinations (Mufanechiya, 2013). In sum, the performance of school children in their various school assessments is supposed to reflect on the grades from their final external assessment. However, this in many instances is not always the case. It is for this reason that Lumpur (2002), stated that the demands for assessment of schools and the needed tools for accomplishing these demands have grown. On the other hand, he stated that a strong doubt remains about the efficacy of such assessments in schools' performance. It is commonplace to observe students with consistent excellent results in internal examinations which do not mirror results obtained in the external assessment (WASSCE). For this reason, it is generally then acknowledged that teachers are not well trained in formative assessment (Hayward, Spencer \& Simpson, 2005). The mind-boggling question usually asked by stakeholders in the education sector is the lack of congruence between school-based student assessment and external assessment scores in subjects taught at that level. Specifically, the study focused on the following objectives: To ascertain if any association exists between the internal and the external assessments scores of students in core mathematics in the selected school; and to establish another prognostic model for internal and external assessment particularly feasible for the Ghanaian teaching and learning context.

\section{Theoretical review}

\subsection{Conceptual difference between internal and external assessments}

According to Aijaz (2011), internal assessment is often called "home examination", "classroom test" or "teacher made test". According to the author, internal assessment could also be in a form in which all the arrangements are made by the teachers of the same institution. On the other hand, Nsgmedico (2014) stated that external assessment is a tool (standardised examination(s)) which is set by a governing body and is employed by non-biased personnel. The author emphasises that external assessments are designed, selected, and controlled by other persons or groups of commercial publishers, district administrators, or state policymakers.

Laraib (2015) in his comparison of internal assessment (tests, quizzes) with external assessment (standardised examination) noticed that one of the major disturbing differences between internal assessment and external assessment is that regarding internal assessment teachers within the school can possibly give hints to students about the nature of the assessment, which certainly defeats the aim of assessment which, invariably, is to challenge learners. Some objectives of external assessment include: to award the students with a terminal certificate; to maintain standards of education; to place the students on a scale of merit; for comparison of their abilities; to evaluate the progress of institutions; to aid selection for higher education; popularity/standard of educational institutions; selection of intelligent students; evaluation of teacher's performance; evaluation of curriculum objectives and creation of good study habits in students (Laraib, 2015).

These objectives are different from the objectives of internal assessment which include: to evaluate the mental nourishment of students; to estimate the student's educational progress, speed of achievement and learning ability; it creates a competing environment with its attendant motivational effects on learners; it also aids teachers to evaluate their progress and their teaching methods and try to overcome their weakness; beyond that parents of students are informed about the progress of students so that they can assist to mitigate such deficiencies; it helps teachers to know the hidden abilities, capabilities, desires and interests of the students, and able to guide them accordingly (Aijaz, 2011). 


\subsection{Internal assessment and its role}

Internal assessment, or curriculum-embedded assessment, evaluates what students do when they are in the classroom. Internal assessment is a crucial part of the instructional process and enables teachers, students, and parents in evaluating student progress. Internal assessment illustrates aspects of student progress that are not typically evaluated in external assessment.

Internal assessments can serve two different purposes. The first ('formative assessment') is to help students to find out what they should do and how. The second (summative assessment) is to gather information to inform others about the progress a student has made so far (Krieken, 2006). It must be emphasised that internal assessment also serves as a basis for professional development. Teachers who analyse the work of their students will normally see trends in student performance that may be related to instruction. For example, teachers who notice that their art students' products lack depth may wish to introduce advanced content to elicit more depth in student performance.

\subsection{External assessment and its role}

The main objective of external assessment is to provide evidence on student learning in the education system. More specific objectives according to Kellaghan (2009) may also be stated: for example, to establish the current reading standards of fourth-grade pupils; to compare student achievements in private and public schools; to monitor trends in student learning over time; to describe school resources; to examine school, home background, and pupil factors that may be related to reading achievement; and to provide a basis for future assessments. The central unit of education normally would want to be sure that the classroom teacher is doing what is expected of him consistently. The measure of this is done through external assessment. For this reason, Rey (2010) indicated that external assessments were used for a number of reasons including; to provide teachers and education professionals with feedback and comparative evaluations; to diagnose the state of the education system as a whole; provide objective information for school users; and assess the effective acquisition of learning by students. According to him, one of the chief purposes of the current use of external assessment is assessing and steering education systems. The importance of external assessment is enormous, hence the reason why many countries of which Ghana is not an exception have embraced it. The United kingdom and France are typical cases in point; they appear to be the epitome of modern standardised assessment, hence their education system has a long-standing tradition of using large-scale external assessments at the end of higher secondary education ('baccalaureate') for qualifying and summative assessment (transition from secondary to higher education); and for assessing overall student performance(Rey, 2010).

According to the most recent Eurydice report (2009), only five countries have not introduced national student assessments: The Czech Republic, Greece, Wales, Liechtenstein and the German Community of Belgium. National states seek to carry out more effective assessments of the quality and effectiveness of teaching using more rigorous and effective indicators. In this way, assessment is used as a tool for monitoring education systems (Rey, 2010). On the role of external assessment, Mangez and Cattonar (2009) suggest that external assessment surveys provide the OECD with the academic credibility required to promote political orientations on educational issues. Under the banner of a neutral and objective diagnosis of education systems, PISA might, thus, serve as a means of promoting specific orientations on curriculum issues (for example, promoting skills rather than the transmission of academic knowledge). The idea is that increased knowledge of the results of teacher activity on student learning (particularly among teachers) will encourage teachers to improve their practice. As summarised by Halasz (2006): Some argue that a relatively stringent level of accountability in which results are made public and have significant implications in an educational market is the best way to improve the quality and performance of educational service.

\subsection{Correlation between external and internal assessments}

Ochieng (2012) in his study on "predictive validity of internal examinations in the secondary school in Kenya" using a descriptive research design with his target population being the students from year 4 secondary schools who registered in Form 1 in 2007, and sat for their KCSE examination in 2010. Examination scores for internal summative examinations and KCSE examination scores for 60 students from year 1 in 2007 to year 4 in 2010 were purposively sampled from each of the four schools targeted making a sample of 240 students. The instrument that was employed in data collection was an inventory. The inventory requested test scores derived from tests constructed, administered, and scored by teachers in secondary schools for mathematics, English, Biology and Geography. Data was analysed using quantitative statistics. The relationship between the scores was determined by calculating correlation coefficients and results presented using tables and graphs with the aid of SPSS.

The study found that there was a significant relationship between the internal summative examination scores and the external public summative examination scores with mathematics as a major predictor of student performance and that the students' performance in the internal summative examination in first year could not be used to predict the performance in the external summative examination. Fourth year was a major predictor followed by the performance in third year and then finally the performance in second year. 
A research on predictive validity of internal examination was also carried out by Omirin and Ale (2008), to investigate the predictive validity of English and Mathematics mock examination results of senior secondary school students' performance in WASCE in Ekiti-state, Nigeria. Three hundred and sixty (360) students were selected by simple random sampling technique from twelve public secondary schools in six local government areas of Ekiti State, Nigeria. The study made use of the already existing data of the results of WASCE of students and unprocessed raw scores of mock examinations from various selected schools. Mock English and Mathematics scores helped significantly in predicting the success in academic performance of students in WASCE. However, English was a better predictor of success than mathematics. It was then recommended that Mock examination should be made compulsory for students intending to sit for WASCE as it had been found helpful in predicting their performance simply because both internal and external assessment were judged to correlate positively.

In addition, Adeyemi (2008) examined the relationship of the Junior Secondary Certificate (JSC) examination performances with that of the performance of students in the Senior Secondary Certificate (SSC) examinations in Ondo State. The study revealed that JSC examinations were a good predictor of performance at SSC examinations.

Additionally, the American Institute of Research, in collaboration with the College Board, in a study of approximately 1,200 first year students from 13 colleges examined the predictive and placement validity of new Scholastic Achievement Test (SAT) writing section. The prototype evaluated was 10 minutes shorter and had 12 fewer questions than the operational new writing section had. The results indicated that total scores on the writing section correlated about 0.46 with first-year college grades ( 0.46 versus 0.43$)$, the SAT writing scores were slightly worse than high school grades (Kobbrin and Schmidt, 2006). Even though teacher-assessed course components do not necessarily assess with the same rigour as external components, it is argued that correlation between the two forms are intimately linked. Finally, Krieken (2006) is of the view that internal assessment and external exams should not be seen as alternatives, but as instruments that need to be used with care, and for the purpose they serve best.

\subsection{Methodology}

The deductive approach was the design of choice for study. It entailed the use of both primary and secondary data. Longitudinal data consisting of 111 students together with their corresponding scores of internal and external assessments spanning their second circle education in the selected public senior secondary school between 2013 and 2016 constituted the secondary data for the study; such data was made available at the school's administration incharge of student information. Further, primary data for the study were collected with the help of a questionnaire consisting of both closed and open-ended questions and administered through face-to-face interaction with students and teachers at the school. Data was analysed using the SPSS software version 13. The study data were present in the form of descriptive and analytical statistics, notably: correlation coefficients, paired sample t-test and regression curves.

\subsection{Results and discussions}

Paired sample statistics: the study explored the paired statistics in students mean performances considering their first and second-year assessment results.

Table 1. comparison of year one and year two assessment results

t-Test: Paired Two Sample for Means

\begin{tabular}{llll}
\cline { 1 - 2 } & $\begin{array}{l}\text { First year } \\
\text { assessment results }\end{array}$ & $\begin{array}{l}\text { Second year } \\
\text { assessment results }\end{array}$ & \multirow{2}{*}{0.77} \\
\cline { 1 - 3 } Mean & 51.10 & 50.32 & 10.65 \\
Observations & 111 & 111 & 1.01 \\
Standard deviation & 17.62 & 14.12 & \\
Standard error mean & 1.67 & 1.34 & \\
Pearson Correlation & 0.80 & & \\
Sig. (2-tailed) for correlation & 0.00 & 110 & 0.45 \\
Df & 110 & & \\
Sig. (2-tailed) for t-test & & & \\
\hline
\end{tabular}

2.2 Applications of $H M S$

The findings of the survey result revealed that the average student score in mathematics for year one was 51.10 at a standard deviation of 17.62. Nonetheless, the mean score in mathematics of the same students for their secondyear assessment dropped to 50.32 at a standard deviation of 14.12. Thus, the data suggested a decline in student performance over time. The finding depicts that there were variations in the scores of the students in the internal assessment (17.62) as compared with the external assessment (14.12). It was further found that both means were not far from correct as minimal mean errors were recorded. 
In addition, a significantly positive relationship $(\mathrm{r}=0.80,0.000<0.05)$ was realised from the correlation. There was a steady increase in scores of the same cohort of students over time (from year 1 to year 2). Alternatively, it can be said that the scores of the students in their internal assessment in year one was directly related to scores obtained in year 2 in mathematics.

Furthermore, comparing the average scores of the students in core mathematics in year one (average score = 51.10 ) against assessment in year two (average score $=50.32$ ), a mean score difference of 0.77 was obtained at a high deviation of 10.65 with a mean error of 1.01. It thus shows that, there were greater variations in the students' scores in both assessments notwithstanding the small mean error recorded. It was however found not to be significant at 5\%. This however implies that there is no significant difference between the scores of students in core mathematics in year one assessment as against assessment in year two in mathematics.

Following is a graphical illustration of the results of the students.

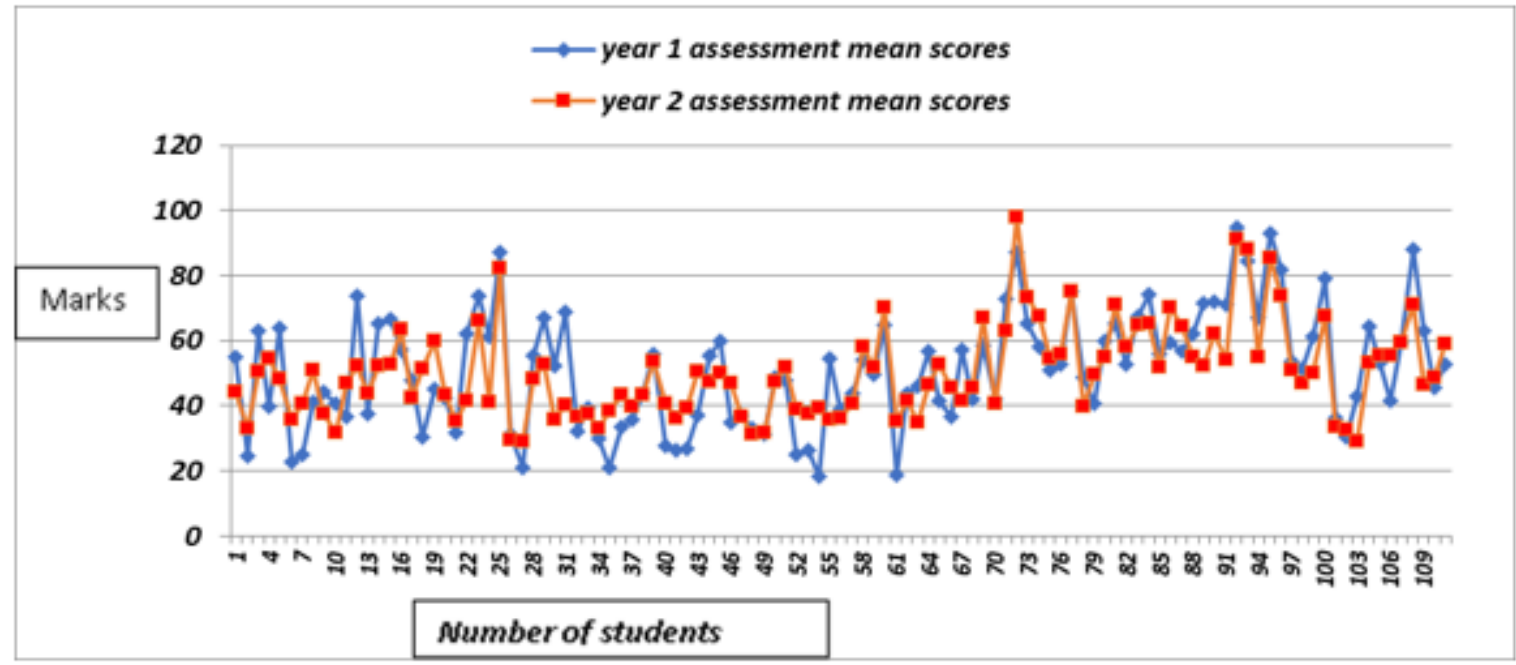

Figure 1: illustration of year 1 and year 2 assessments mean scores

A glance at figure 1 indicates that the lowest mean score for year one assessment was slightly below 20; in total, about 61 students scored between 18 and 20 marks. The highest marks attained by year 1 students was in the region of 98 marks; a total of about 95 students attained that high mark; nonetheless, the mean score for this year group was 51.10. This demonstrates an average threshold attained in class assignments (tests internal exams). The data for year 2 students appears to have fallen (47.61) below that that of year 1 performance notwithstanding some clusters of higher marks at the individual level.

Table 2: comparison of internal assessment (First year) and external assessment results

t-Test: Paired Two Sample for Means

\begin{tabular}{|c|c|c|c|}
\hline & $\begin{array}{l}\text { First } \quad \text { year } \\
\text { assessment results }\end{array}$ & $\begin{array}{l}\text { External assessment } \\
\text { (WASSCE) }\end{array}$ & Difference in Means \\
\hline Mean & 51.10 & 47.61 & 3.49 \\
\hline Observations & 111 & 111 & \\
\hline Standard deviation & 17.62 & 10.74 & 13.26 \\
\hline Standard error mean & 1.67 & 1.02 & 1.26 \\
\hline Pearson Correlation & 0.66 & & \\
\hline g. (2-tailed) for correlation & 0.00 & & \\
\hline Df & 110 & 110 & \\
\hline Sig. (2-tailed) for t-test & & & 0.007 \\
\hline
\end{tabular}

Sig. (2-tailed) for t-test

Again, the study tried to determine whether students were able to maintain the scores they had in mathematics when they were in year one (internal assessment), in their final WASSCE assessment (external assessment). It was revealed from the data that, the internal assessment mean score (51.10) was above the external assessment mean score (47.61). Similarly, both the standard deviation (17.62) and the standard error of mean (1.67) of the internal assessment scores were comparatively higher than the external assessment figures: standard deviation (10.74) and standard error of mean (1.02). This seems to suggest that the disparity between the internal and external assessment scores was higher. On the account of the variation that existed within the scores of students, it is clear that the variation in the scores of the students in their first year (17.62) was higher than the variation in their scores in the external assessment (10.74).

The findings also suggest a significantly $(0.000<0.05)$ positive correlation $(\mathrm{r}=0.66)$ between the respondents first year assessment (internal assessment) and the external assessment (WASSCE). This also implies that as the performance of the students in the internal assessment increases, it is most likely (i.e. $66 \%$ probability) that their 
performance in the external assessment would increase likewise.

Moreover, a significant $(0.00<0.007)$ difference was notice between the mean score of respondents obtained from their first-year examination (internal assessment) in mathematics (51.10) and that of their results obtained in WASSCE examination (external assessment) (47.61). However, the deviation from the mean (1.29) was 13.26 with a minimal standard error mean of (1.26), implying that though there were high variations among students scores, the mean difference was close to the actual mean. It therefore stands to reason that students in SHS perform better in their first-year assessment than in their WASSCE assessment (External assessment). These findings corroborate with those of Ochieng (2012) in his study titled "predictive validity of internal examinations in the secondary school in Kenya" in which he demonstrates that students' performance in internal summative examination in first year could not be used as a basis to predict the performance in the external summative examination.

Table 3: comparison of internal assessment (year 2) and external assessment (WASSCE)

\begin{tabular}{|c|c|c|c|}
\hline \multicolumn{3}{|c|}{ t-Test: Paired Two Sample for Means } & \multirow[b]{2}{*}{ Difference in Means } \\
\hline & $\begin{array}{l}\text { Second year } \\
\text { assessment results }\end{array}$ & $\begin{array}{l}\text { External assessment } \\
\text { (WASSCE) }\end{array}$ & \\
\hline Mean & 50.32 & 47.61 & 2.71 \\
\hline Observations & 111 & 111 & \\
\hline Standard deviation & 14.12 & 10.74 & 9.87 \\
\hline Standard error mean & 1.34 & 1.02 & 0.94 \\
\hline Pearson Correlation & 0.72 & & \\
\hline Sig. (2-tailed) for correlation & 0.00 & & \\
\hline Df & 110 & 110 & \\
\hline Sig. (2-tailed) for t-test & & & 0.005 \\
\hline
\end{tabular}

In determining whether students were able to maintain scores they had in mathematics in year two (internal assessment) in their final WASSCE assessment (external assessment), the researchers noticed that the internal assessment mean score (50.32) was higher than the external assessment mean score (47.61). In the same way, both the standard deviation (14.12) and the standard error of means (1.34) of the internal assessment results were also higher than the external assessment standard deviation (10.74) and standard error of means (1.02); suggesting that the variation in the internal assessment scores (second year results) was equally higher than the variation in the external assessment results; notwithstanding the mean errors of both means were small signifying that the means were close to the actual means.

The study noticed a significantly $(0.000<0.05)$ positive correlation $(r=0.72)$ between the scores of students in their second-year assessment and that of the external assessment. This signifies that the scores of the students in internal assessment were directly related to their scores in the final assessment (WASSCE assessment). The mean comparison of the average score (50.32) of students in mathematics in their second year with the average score $(47.61)$ of these same students in their WASSCE 2016 taken, shows a significant $(0.00<0.005)$ mean difference (that is 2.71 at a standard deviation of 9.87 and a standard error of mean 0.94). The standard deviation above shows that there is a variation among the scores of the students in both assessments. It can be inferred that the performance of students in their final examination (external assessment) is lower than their performance in the internal assessment of the school.

Table 4: comparison of internal assessment average (year 1-3 average) and external assessment (WASSCE)

\begin{tabular}{|c|c|c|c|}
\hline \multicolumn{3}{|c|}{ t-Test: Paired Two Sample for Means } & \multirow[b]{2}{*}{ Difference in Means } \\
\hline & $\begin{array}{l}\text { Year } 1-3 \text { average } \\
\text { result }\end{array}$ & $\begin{array}{l}\text { External assessment } \\
\text { (WASSCE) }\end{array}$ & \\
\hline Mean & 60.85 & 47.61 & 1.32 \\
\hline Observations & 111 & 111 & \\
\hline Standard deviation & 18.07 & 10.74 & 12.70 \\
\hline Standard error mean & 1.71 & 1.02 & 1.21 \\
\hline Pearson Correlation & 0.72 & & \\
\hline Sig. (2-tailed) for correlation & 0.00 & & \\
\hline Df & 110 & 110 & \\
\hline Sig. (2-tailed) for t-test & & & 0.00 \\
\hline
\end{tabular}

The study ascertained a higher mean score (that is 60.85 at a standard deviation of 18.07 and a standard error of mean 1.71) of the internal assessment (end of terms assessments) took by the students from 2013 to 2016. This mean is higher than the mean score (that is 47.61 at a deviation of 10.74 and a standard error of mean 1.02) for the respondents' marks obtained from the external assessment (WASSCE) in the year 2016. The illustration in table 4 shows that there is a high variation among the scores of the students in the internal assessment results (18.07) in 
core mathematics than as it is in that of the external assessment $(10.74)$. The mean errors $(1.71 \& 1.02)$ depicts that the means $(\pi=; 60.85,47.61)$ were not so much far from the actual means.

Adding to that, a significantly $(0.00<0.05)$ positive relationship $(0.72)$ was identified for the correlation between the scores of respondents in the internal assessment and that of their scores in the external assessment. The correlation realized was very strong implying that an increase in scores of one of the assessment leads to an increase in the students' scores in the other. Thus, the two assessments directly relate to each other. This finding is in congruence with the study of Omirin and Ale, (2008) who assessed the validity predictive ability of mathematics and English language mock examination scores of Senior Secondary school WASSCE in Ekiti-state within Nigeria and noticed that there was a correlation.

Generally, the comparison of the mean mark (60.85) of the internal assessment taken by the students in the SHS with the mean mark (47.61) of the external assessment sat for by the same students at the end of their second cycle education, pop up with a mean mark difference of 1.32 at a standard deviation of 12.70 and a mean error 1.21. The standard deviation shows that there was a high variation among the scores of the students, while the mean error also shows that the mean difference was close to the actual means. The mean mark (1.32) difference was deemed significant $(0.00<0.05)$.

Overwhelmingly, a great difference was noticed between the internal assessment and the external assessment results as the mean mark difference was significant. This also signifies that there is a difference existing between the internal assessment at the SHS and that of the external assessment which is often organised for final year students by the West Africans Examination Council. It can be inferred that teachers probably hint students about the internal assessment, which give them an idea of the nature of the question, a probable reason why students perform better in internal assessment than in external assessment.

This finding totally agrees with the finding of Laraib (2015) who compared internal assessment (examination) with external assessment (examination) in his masters of philosophy studies, where he notices that one of the major disturbing difference between internal assessment and external assessment is that, in internal assessment teachers within the school possibly give hints to students about the nature of the assessment, which according to him defeat the aim of assessment which is to challenge learners.

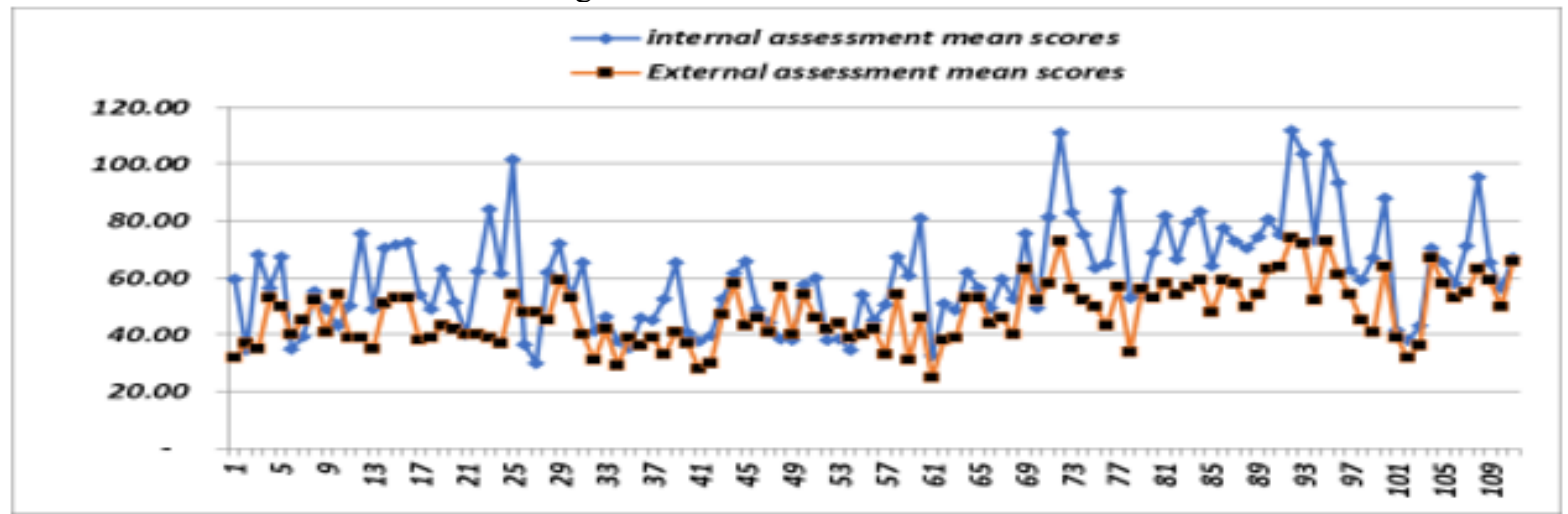

Figure 2: illustration of internal assessments average (year $1-3$ average) and external assessment

Table 5: Predictive model for year one assessment and external assessment (WASSCE)

\begin{tabular}{|lll|}
\hline \multicolumn{1}{|c|}{ Model Summary } & \\
\cline { 1 - 2 } $\mathrm{R}$ & $\begin{array}{l}\text { Internal assessment (year } \\
\text { one results) }\end{array}$ & \\
R Square & 0.66 & \\
Adjusted R Square & 0.436 & \\
Std. Error & 0.431 & 2.37 \\
Coefficients (B) & 0.04 & 27.10 \\
Beta & 0.41 & \\
T & 0.66 & 11.43 \\
Sig. & 9.19 & 0.00 \\
\hline
\end{tabular}

From table 5 above, an $\mathrm{R}$ square value of 0.44 was obtained for the model implying that above $44 \%$ of the disparity in the scores of the students in the external assessment is accounted for by the model.

The Simple linear model for predicting the results of the students' scores in the external assessment using the internal assessment (i.e. year one results) is $\mathrm{Y}=27.10+0.41 \mathrm{X}$. Where $\mathrm{Y}$ is scores in the external assessment (dependent variable) and $\mathrm{X}$ is the average score of all the internal assessment in the first year of the respondents 
in the school (independent variable). From the linear model, the coefficient of assessment at year one in table 5 is 0.41 , meaning a one percent increase in a student score from the assessment at year one by a student would lead to a 0.41 increase in his score in the external assessment. The regression constant $(B=27.10)$ also shows that if a student scores an additional zero percent in one of his year one assessment (that is $\mathrm{X}=0$ ) his marks in the external assessment will be $27.10 \%$.

Table 6: Predictive model for assessment at year two against external assessment

\begin{tabular}{|lll|}
\hline \multicolumn{1}{|c|}{ Model Summary } & \\
\cline { 1 - 2 } $\mathrm{R}$ & $\begin{array}{l}\text { Internal } \begin{array}{c}\text { assessment } \\
\text { (year two results) }\end{array} \\
\text { R Square }\end{array}$ & \\
Adjusted R Square & 0.72 & \\
Std. Error & 0.51 & 2.56 \\
Coefficients (B) & 0.51 & 20.19 \\
Beta & 0.05 & \\
T & 0.55 & 7.61 \\
Sig. & 0.71 & 0.00 \\
\hline
\end{tabular}

From table 6 above, an $\mathrm{R}$ square value of 0.51 was obtained for the model implying that about $51 \%$ of the disparity in the scores of the students in the external examination is also accounted for by the model. The linear model for predicting the results of the SHS students' scores in the external assessment from the internal assessment (year two assessment) is $\mathrm{Y}=20.19+0.55 \mathrm{X}$. Where $\mathrm{Y}$ is score in the external assessment (dependent variable) and $\mathrm{X}$ is the average score of all the internal assessments of the second year of the students at the school (independent variable).

From the linear model, the coefficient of assessment at year two in table 6 is 0.55 , meaning an increase in a student score from the assessment at year two by one would lead to a 0.55 increase in his score in the external assessment. The regression constant $(B=20.19)$ also shows that if a student scores an additional zero percent in his year two assessment (that is $\mathrm{X}=0$ ) his mark in the external assessment will be $20.19 \%$. Table 7: Predictive model for internal assessment and external assessment

\begin{tabular}{|c|c|c|}
\hline \multicolumn{2}{|l|}{ Model Summary } & \multirow{3}{*}{ Constant } \\
\hline & $\begin{array}{l}\text { Internal assessment (year } \\
1-3 \text { results) }\end{array}$ & \\
\hline $\mathrm{R}$ & 0.72 & \\
\hline R Square & 0.52 & \\
\hline Adjusted R Square & 0.52 & \\
\hline Std. Error & 0.04 & 2.50 \\
\hline Coefficients (B) & 0.43 & 21.50 \\
\hline Beta & 0.72 & \\
\hline $\mathrm{T}$ & 10.92 & 8.60 \\
\hline Sig. & 0.00 & 0.00 \\
\hline
\end{tabular}

From table7 above, an R square value of 0.52 was obtained for the model implying that above $52 \%$ of the disparity in the scores of the students in the external examination is accounted for by the model. That notwithstanding, the adjusted R square was still maintained as the R Square value $(52 \%)$, which is a measure of the model fit, if the total of the results of the students in the internal assessment (i.e. independent variable) is to be adjusted.

The linear model for forecasting the performance of the students' scores in the external assessment from the average score of students for all the internal assessment is $\mathrm{Y}=21.50+0.43 \mathrm{X}$. Where $\mathrm{Y}$ represents scores in the external assessment (dependent variable) and $\mathrm{X}$ is the average score for all the internal assessments (independent variable).From the linear model, the coefficient of the internal assessment in table 7 is 0.43 , meaning an increase in a student score from the internal assessment by one would lead to a 0.43 increase in his score in the external assessment. The regression constant $(\mathrm{B}=21.50)$ in table 7 also shows that if a student scores an additional zero percent in one of his internal assessment (that is $\mathrm{X}=0$ ) his mark in the external assessment would be $21.5 \%$. Consequently, the model has a significant predictive ability This implies that the independent variables (internal assessment average scores) can be relied on for effective prediction of the dependent variable (external assessment scores).

\section{Study findings}

Firstly, the data indicated that the average results of year one students in internal assessment $(\pi=51.10)$ of the selected school was higher than their average score for core mathematics in second year internal assessment $(\pi$ 
$=50.32$ ). The first-year average score of students in core mathematics (internal assessment) from the data showed a strong positive correlation $(\mathrm{r}=0.80,0.000<0.05)$ with year two mean score in the school internal assessment. The general outcome of the comparison of the year one average score of students in mathematics with the mean score in year two assessment of the students indicates that there was a statistically insignificant difference $(\pi=$ $0.77,0.45>0.05)$ in the means of the two assessments.

The study further shows a statically significant mean difference $(\pi=3.49,0.007<0.05)$ between the mean score of students in their first year and the mean score of students in the external assessment (WASSCE). A strong significantly positive correlation $(\mathrm{r}=0.66,0.000<0.05)$ was also identified between the two assessments.

In addition, the study revealed that the mean score of year two students in the school assessment $(\pi=50.32)$ was more than the mean score of students in the external assessment (WASSCE) $(\pi=47.61)$ they finally sat for. The average score difference between the two assessments was identified to be statistically significant. A significant correlate $(r=0.72,0.000<0.05)$ was also found between these assessments.

The overall comparison of the mean score $(\pi=60.85)$ of students in all the internal assessment with the mean score $(\pi=47.61)$ of students in the external assessment in mathematics revealed a significant mean difference $(\pi$ $=1.32,0.000<0.05)$ between the mean scores of the two assessments. The two assessments results were identified to be statistically and significantly correlate $(\mathrm{r}=0.72,0.000<0.05)$.

Furthermore, the following models for the prediction of the students' results for different assessments were discovered:

Model one: $\mathrm{Y}=27.10+0.41 \mathrm{X}$

Model two: $\mathrm{Y}=20.19+0.55 \mathrm{X}$

Model three: $\mathrm{Y}=21.50+0.43 \mathrm{X}$

In all the models, $\mathrm{Y}$ stands for the external assessment result of a student, while $\mathrm{X}$ stands for the internal score of a student in mathematics in first year, second year and in the overall average score of a student in all the internal assessments of the school for model one, two and three respectively. All the models were realised to have a predictive capacity of $50 \%$ and above.

\section{Conclusions and recommendation}

Based on the findings of the study conducted on the comparison of internal assessment and external assessment results of the Senior High School students in core mathematics, the followings conclusions were reached. In sum, it was concluded that the average performance in external assessment was lower than the average performance in the internal assessment. The study also confirmed that irrespective of the stage of a student's performance, internal assessment can successfully predict performance in the external assessment of the subject under study with either of the follow models; $\mathrm{Y}=27.10+0.41 \mathrm{X}, \mathrm{Y}=20.19+0.55 \mathrm{X}$ and $\mathrm{Y}=21.50+0.43 \mathrm{X}$. These models are useful to the external assessment administrators, as they may enable them to award scores for missing results or detect cheating among students. Consequently, it was noted that the general difference that existed between the performance of students in internal and external assessment of mathematics was that student scores in internal assessment in the subject were always higher comparatively.

\section{Recommendations}

The study recommends the following based on the study results:

- Students are encouraged to put more effort in the study of mathematics and assessments (internal assessment) while in the school, since that contributes in large measure in predicting their performance in the external assessment.

- Teachers are exhorted to step up strategies to enhance student learning in the final year (form 3) since performance in internal assessment at that stage contributes more than any other year in predicting their performance in the external examination.

- Students who perform poorly in year one should not be discouraged; since personal remedial action could be taken; also, students who perform better in first year should maintain the effort consistently throughout their stay in school, for, school assessment scores were key predictors of performance in the external assessment

\section{References}

Adeyemi, T.O. (2008). Predicting students' performance in Secondary Certificate Examinations from performance in Junior Secondary Certificate Examination from performance in Junior Secondary Certificate Examinations in Ondo State Nigeria. Humanity and Social Sciences Journal 3 (1); 26-36.

Aijaz, A.G. (2011). "Internal Versus External Assessment” http://www.articlesbase.com/college-and-universityarticles/internal-versus-external-assessment-4098869.html.Accessed on 09-11-19.

Baumgartner, T.A., Strong, C.H. and Hensley, D.L. (2002). Conducting and Reading Research in Health and Human Performance (3rd ed.). McGraw Hill Companies Inc. New York. 
Bureau, V., \& Houlberg Salomonsen, H. (2012). Comparing Comparative Research Designs. Working Papers from Department of Political Science. Fibigerstræde 1DK-9220 Aalborg. ISSN: 1396:3503ISBN: 978-8792174-48-22012:1 Aalborg 2012

Burns, N., \& Grove, S.K. (2009). The practice of nursing research: Appraisal, synthesis, and generation of evidence. St. Louis, MO: Saunders Elsevier.

Fernley, F., (2015). "Glossary of Important Assessment and Measurement Terms "NCME100N. 20th Street, Suite 400, Philadelphia, PA,19103I P: (215) 461-6263 F: (215) 564-2175

Giacomini, R., \& White, H. (2006), “Tests of Conditional Predictive Ability" Econometrica, 74 (6): 1545-1578

Glossary Letter, E. (2011), "In Journal of Clinical Oncology" http://jco.ascopubs.org/cgi/glossarylookup=by_letter\&letter=E.Accessed on November 2019.

Gonnela, E., \& Rothstein, H. (2004), "an empirical study of predictive validity of number grades in medical school using 3 decades of longitudinal data: Implications for grading system Medical Education, 38(4), 425 - 434.

Grauwe, D. A. (2008), "School Supervision in Four African Countries" Volume 1: Challenges and Reforms. Paris: IIEP.

Halasz. (2006). "Schools for Quality: What Data-based Approaches Can Contribute" Sint-Katelijne-Waver: Consortium of Institutions for Development and Research in Education in Europe (CIDREE). Available: http://www.cidree.be/uploads/documentenbank/d3df7cd6c6a61f9d70302ba2a370bb08.pdf

Hayward, L., Spencer, E., \& Simpson, M. (2005). "Assessment Is for Learning: Exploring Programme Success" neural networks Journal of the American Society for Information Science and Technology, 60(2), 372-380.

Katelijne-Waver: Consortium of Institutions for Development and Research in Education in Europe[online]. Available: http://www.cidree.be/uploads/documentenbank/d3df7cd6c6a61f9d70302ba2a370bb08.pdf.

Kellaghan, T. (2009). "Monitoring performance: Assessment and Examinations in Africa" Association for the Development of Education in Africa (ADEA) International Institute for Educational Planning

Kobbrin and Schmidt (2006), "predictive and placement validity of new Scholastic Achievement Test (SAT) writing section"

Krieken, R., V. (2006). "Literature review on internal assessment for the National Qualifications for the Future project" Policy and new products research report 11. http://www.sqa.org.uk/files_ccc/PNP_ResearchReport11_LiteratureReviewlinternalAssessment.pdf. Accessed on November 2019

Kusi, H. (2012). "Doing qualitative research: A guide for researchers" Accra New Town: Emmpong Press.

Laraib (2015), "Trends and Issues in Education; Internal Versus External Examination" Education University of Gujrat, Department of Education University. Session 2015- 2017

Lingard, B., Mills, M., and Hayes, D. (2006). "Enabling and aligning assessment for learning: some research and policy lessons from Queensland" International Studies in Sociology of Education, 16 (2) 83-103

Lowis, M., \&Castley, A. (2008). "Factors affecting student progression and achievement: Prediction and intervention" Innovations in Education and Teaching International, 45(4), 333-343.

Lumpur, k. (2002), "Schools Evaluation for Quality Improvement" Paris2004, UNESCO: International Institute for Educational Planning. http://www.unesco.org/iiep. Accessed on 21/11/16.

Mangez, E. and Cattonar, B. (2009). "The status of PISA in the relationship between civil society and the educational sector in French-speaking Belgium" Sísifo Educational Sciences Journal, 10, 15-26 [online]. Available: $\mathrm{http}: / /$ sisifo.fpce.ul.pt/?r=25t

Mufanechiya, A. (2013). "The Relevance of Internal and External Examinations In Zimbabwean Secondary Schools" Greener Journal of Educational Research ISSN: 2276-7789 Vol. 3 (7), pp. 326-331, November, 2016.

Nelson, R., Dawson, P. (2014). "A contribution to the history of assessment: how a conversation simulator redeems Socratic method". Assessment \& Evaluation in Higher Education. 39 (2): 195-204.doi: 10.1080/02602938.2013.798394or-improvement/

Nihalani, P. K., Wilson, H. E., Thomas, G., \& Robinson, D. H. (2010). What determines high- and low-performing groups? The superstar effects. Journal of Advanced Academics, 21(3), 500-529.

Nsgmedico (2014). "External Assessment- Definition, process, importance, advantages, disadvantages, suggestions for improvement" http://www.nsgmed.com/education/external-assessment-definition-processimportance-advantages-disadvantages-suggestions-. Accessed on 09-10-19.

Omrin. M.S. \& Ale R.M. (2008). Predictive validity of English and Mathematics Mock Examination Results of Senior Secondary School student's performance I WASCE in Ekiti - State, Nigeria. Pakistan Journal of Social Sciences 5 (2); 139- 141.

Onwuegbuzie, A. J., Collins, K. M. T., \&Elbedour, S. (2003). Aptitude by treatment interactions and Matthew effects in graduate-level cooperative-learning groups. The Journal of Educational Research, 96(4), 217.

Ochieng, P. A. (2012). Predictive validity of internal examinations in secondary schools in Kenya (Doctoral dissertation, University of Nairobi). 
Rey, O., (2010). "The use of external assessments and the impact on education systems" Beyond Lisbon 2010: perspectives from research and development for education policy in Europe. Use of Results [online]. Available: http://eacea.ec.europa.eu/education/eurydice/thematic_studies_en.php [19 -08- 2019]

Thomas B. F. (2001). "Work groups and teams in organisations". Retrieved [24-03-17], from Cornell University, ILR School site: http://digitalcommons.ilr.cornell.edu/articles/389

Veenstra, C. P., Dey, E. L., \& Herrin, G. D. (2008). Is modeling of freshman engineering success different from modeling of non-engineering success? Journal of Engineering Education, 97(3), 467-479.

Ware, W. B., \&Galassi, J. P. (2006). Using correlational and prediction data to enhance student achievement in K12 schools: A practical application for school counselors. Professional School Counseling, 9(5), 344-356.

Zufanová $\mathrm{H}$. On the meaning of internal and external evaluation for the quality of education during educational reforms // Schools for quality - what data-based approaches can contribute. CIDREE/DVO, 2006. P. 35-55. 